\title{
1 A study on the longitudinal compression strength of fibre reinforced 2 composites under uniaxial and off-axis loads using cross-ply laminate 3 specimens
}

4 Daniel Thomson ${ }^{\mathrm{a}}$, Hao Cui $^{\mathrm{b}, *}$, Borja Erice $^{\mathrm{a}, \mathrm{c}}$, Nik Petrinic $^{\mathrm{a}}$

5 aDepartment of Engineering Science, University of Oxford, Oxford, United Kingdom

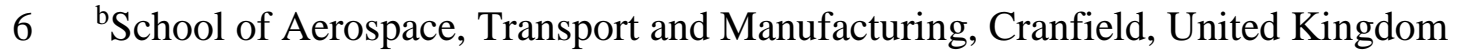

$7 \quad$ 'Structural Impact Laboratory (SIMLab), Department of Structural Engineering,

8 Norwegian University of Science and Technology (NTNU),

9 Richard Birkelands vei 1A, NO-7491 Trondheim, Norway

\section{Abstract}

11 Longitudinal compression testing of unidirectional FRP laminates remains a challenge due to the

12 difficulty in applying high compressive loads without stress concentrations and boundary effects

13 leading to premature failure. This work aims to critically evaluate different specimen designs and

14 laminate configurations, cross-ply in particular, for the determination of longitudinal compression

15 properties of unidirectional plies.

16 To this end, a comprehensive experimental campaign has been carried out, comparing strength,

17 stiffness, and failure modes across different specimen designs and laminate configurations. The

18 investigated cross-ply specimens produced comparable results without many of the issues observed

19 in the testing unidirectional material and, therefore, are strongly recommended for the determination

20 of longitudinal compressive strength.

21 Finally, the cross-ply material was tested under off-axis compression to study the effects of shear on

22 the longitudinal compression strength using a series of compression specimens cut at different angles

23 between 0 and $15^{\circ}$ to the direction of the laminate.

24 Keywords: Polymer matrix composites; Mechanical properties; Longitudinal compression; Buckling.

\footnotetext{
* Corresponding author, hao.cui@ cranfield.ac.uk
} 


\section{Introduction}

26 The compressive strength in fibre direction is of great interest to the design and analysis of laminated

27 composite structures. The longitudinal compressive failure (so called fibre kinking failure) is

28 triggered by inter-fibre damage, which results in local buckling of fibres causing catastrophic

29 material failure. Much work has been done over the years to try to understand the underlying

30 physical phenomena behind this type of failure and its main contributing factors so that it can be

31 more accurately predicted and designed against [1-5]. However, without accurate or reliable

32 experimental measurements, these theories cannot be properly evaluated. The accurate

33 characterization of the critical load in this failure mode remains problematic because the strength in

34 the fibre direction is much higher than that in the transverse direction, which, if the tests are not

35 designed and carried out correctly, often causes matrix failure to occur before the fibre micro-

36 buckling can occur [6,7].

37 Premature matrix splitting of this kind can be caused by the transverse stresses through the thickness

38 of the laminate that arise due to the Poisson effect and stress concentrations at specimen boundaries.

39 Commonly, the solution to mitigate the effect of boundary conditions has been to add clamping

40 fixtures that strengthen the matrix at the loading ends of the specimen and help to distribute the

41 applied load by transmitting some of the compression through shear in the clamped interfaces $[6,8]$.

42 However, this introduces the risk of new stress concentrations at the fixture boundaries and of over

43 constraining the specimen, making the results highly sensitive to the test operator and set-up

44 conditions, as reported in [6].

45 Another proposed solution has been the use of specimens with waisted cross-section area that 46 prevent fracture from occurring close to the specimen boundaries. However, the change in cross-

47 section along with the relative low strength of the matrix can also cause critical stress concentrations

48 that may eventually lead to premature splitting. 
49 In short, the determination of longitudinal compression strength properties using unidirectional (UD)

50 material can be quite problematic and the high sensitivity to boundary conditions should be a cause

51 for concern any time experiments of this kind are being considered. The large variation in reported

52 compressive strength measurements in $[6,7,9]$ for the UD HexPly ${ }^{\circledR}$ IM7-8552 material system serve

53 as a good example.

54 Because of these issues, the extraction of longitudinal ply properties from multidirectional (MD) or

55 cross-ply (CP) laminates, using classical lamination theory (CLT) has been suggested as a more

56 viable alternative $[6,10,11]$. However, previous experimental studies have always shown significant

57 differences between the strength measurements obtained from UD and MD laminates. For the IM7-

588552 material, for example, Lee and Soutis [6] and Ploeckl et al. [7] reported strength measurements

59 from quasi-isotropic (QI) around 20\% higher than the UD material. The use of CP laminates was

60 also explored in the 1990s [10] and higher strengths than the plain UD material were again observed.

61 Based on this previous work, it remains unclear whether the behaviour of MD laminate

62 configurations under longitudinal compression can be representative of UD material and vice versa.

63 However, if this can be established, the use of MD configurations, which have been shown to solve

64 many of the issues that have plagued longitudinal compression in UD specimens, may alleviate the

65 need for complex fixtures and specimen designs and, in turn, simplify the testing process and

66 increase the level of confidence in the results.

67 Therefore, in this study, a systematic experimental campaign has been carried out to: (i) determine

68 the most suitable test and specimen configurations for the measurement of longitudinal compression

69 strength; (ii) evaluate the equivalence between longitudinal compression properties obtained from

70 UD and CP material, in particular; and (iii) investigate the applicability of $\mathrm{CP}$ material for the 71 determination of UD failure envelope in combined loading cases (longitudinal compression and in-

72 plane shear), which can be used to evaluate 3D fibre kinking failure theories and criteria. 


\section{Methodology and experimental set-up}

\section{$74 \quad 2.1 \quad$ Specimen configuration}

75 The specimens for all experiments were cut from two different HexPly ${ }^{\circledR}$ IM7-8552 [12] composite 76 plates with different ply lay-ups, $\mathrm{UD}\left(\left[0^{\circ}\right]_{26}\right)$ and $\mathrm{CP}\left(\left[0^{\circ} / 90^{\circ}\right]_{4 \mathrm{~S}}\right)$. Both laminates were manufactured 77 together in the same facility to ensure similar quality levels between the two, while noting that local 78 fibre architecture will naturally differ slightly between UD and MD laminates. In addition, all 79 specimens were carefully ground and polished to ensure their two loading faces were parallel with 80 adequate surface quality to a tolerance of $\pm 0.05 \mathrm{~mm}$. This was done, in conjunction with the test set81 up described in section 2.2 , to minimise the possibility of bending in the specimens due to

82 imperfections in the specimen, fixture or test procedure, which could otherwise affect the quality of 83 the results [8].

84 The aim for the first set of experiments was to get an accurate measure of the longitudinal 85 compressive strength of the unidirectional material as well as investigating different specimen 86 designs and the effects of different boundary conditions. The different specimen configurations

87 tested, shown in Figure 1, were (a) a simple unclamped cuboidal (rectangular) specimen (UD Cub), 88 (b) an unclamped waisted, or dog-bone, design (UD DBU), (c) a waisted dog-bone specimen with 89 clamping fixtures (UD DBC), and (d) a clamped dog-bone specimen with adhesively bonded GFRP

90 end tabs (UD tabbed DBC) to relax the constraint of the clamping fixtures on the UD material. A 91 gauge section of $5 \mathrm{~mm} \times 5 \mathrm{~mm}$ was kept constant throughout all specimen designs, with a nominal 92 thickness of $2 \mathrm{~mm}$. 


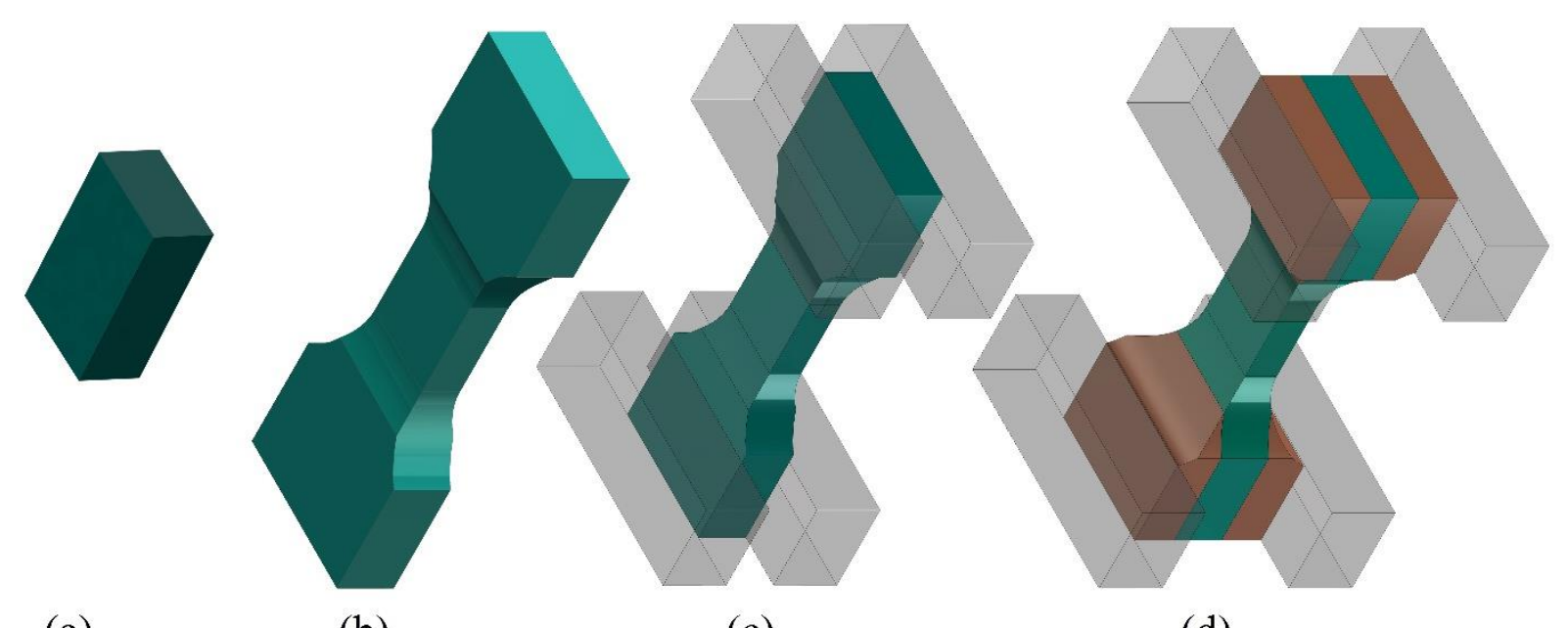

(a)

(b)

(c)

(d)

94 Figure 1. Unidirectional laminate specimen designs: (a) cuboid (UD Cub), (b) unclamped dog-bone

95 (UD DBU), (c) clamped dog-bone (UD DBC), and (d) clamped dog-bone with GFRP end tabs (UD

96 Tabbed $D B C$ ).

97 Next, two different cross-ply specimens were tested to compare against the previous UD results and

98 study whether the effects of the boundary conditions were also as critical on the multi-directional

99 laminate. The specimen configurations, shown in Figure 2, were (a) a simple unclamped cuboid (CP

$100 \mathrm{Cub}$ ) similar to the UD Cub design in Figure 1 (a), and (b) a clamped dog-bone specimen (CP DBC)

101 similar to the UD DBC design in Figure 1 (c). Longitudinal material, or ply properties were extracted

102 from the overall axial response using classical lamination theory (CLT) as described in [11].

103 First the $\boldsymbol{A B D}$ matrix, $\left\{\begin{array}{l}\boldsymbol{N} \\ \boldsymbol{M}\end{array}\right\}=\left[\begin{array}{ll}\boldsymbol{A} & \boldsymbol{B} \\ \boldsymbol{B} & \boldsymbol{D}\end{array}\right]\left\{\begin{array}{l}\boldsymbol{\varepsilon}^{0} \\ \boldsymbol{K}\end{array}\right\}$, which relates the deformation of the laminate given by

104 the in-plane strains $\boldsymbol{\varepsilon}^{0}=\left\{\varepsilon_{11}^{0} \varepsilon_{22}^{0} \varepsilon_{12}^{0}\right\}^{T}$ and the laminate curvatures $\boldsymbol{K}=\left\{\kappa_{11} \kappa_{22} \kappa_{12}\right\}^{T}$ to the

105 resultant in-plane axial forces $\boldsymbol{N}=\left\{N_{11} N_{22} N_{12}\right\}^{T}$ and moments $\boldsymbol{M}=\left\{M_{11} M_{22} M_{12}\right\}^{T}$ per unit 106 width is computed as:

107

$$
A_{i j}=\sum_{k=1}^{n} \bar{Q}_{i j}^{k}\left(z_{k}-z_{k-1}\right)
$$

108

$$
B_{i j}=\frac{1}{2} \sum_{k=1}^{n} \bar{Q}_{i j}^{k}\left(z_{k}^{2}-z_{k-1}^{2}\right)
$$


110 where $\bar{Q}_{i j}$ is the reduced stiffness of each ply, $z$ is the position of the ply from the midplane and $n$ is

111 the total plies in the laminate.

112 Then compound ABD matrix is inverted, which allows for the midplane strains, $\boldsymbol{\varepsilon}^{0}$, and curvatures,

$113 K$, to be determined for a given load using $\left\{\begin{array}{l}\boldsymbol{\varepsilon}^{0} \\ \boldsymbol{K}\end{array}\right\}=\left[\begin{array}{ll}\boldsymbol{A} & \boldsymbol{B} \\ \boldsymbol{B} & \boldsymbol{D}\end{array}\right]^{-1}\left\{\begin{array}{l}\boldsymbol{N} \\ \boldsymbol{M}\end{array}\right\}$.

114 By applying the measured normal compressive load, $N_{11}<0$, the midplane strains for each

115 experiment can be obtained. Then, the stress state of a longitudinal ply can be determined with:

116

$$
\boldsymbol{\sigma}_{\text {long }}=\overline{\mathbf{Q}}_{\text {long }} \boldsymbol{\varepsilon}^{0}
$$

117 Finally, if the material orientation of the ply does not coincide with the global coordinate system, as

118 is the case of the off-axis compression tests in section 3.3, this stress state is then rotated by the off-

119 axis angle, $\alpha$, to give the local stresses in the material direction, $\sigma^{\alpha}=\left\{\sigma_{11} \sigma_{22} \tau_{12}\right\}^{T}$.

$$
\boldsymbol{\sigma}^{\alpha}=\mathbf{R}[\alpha] \boldsymbol{\sigma}_{\text {long }} \quad \text { with } \quad \mathbf{R}[\alpha]=\left[\begin{array}{ccc}
\cos [\alpha] & \sin [\alpha] & 0 \\
-\sin [\alpha] & \cos [\alpha] & 0 \\
0 & 0 & 1
\end{array}\right]
$$

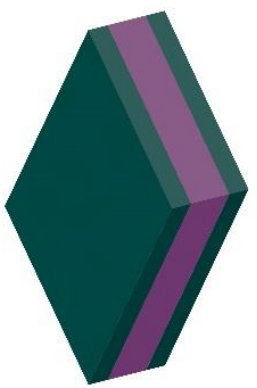

(a)

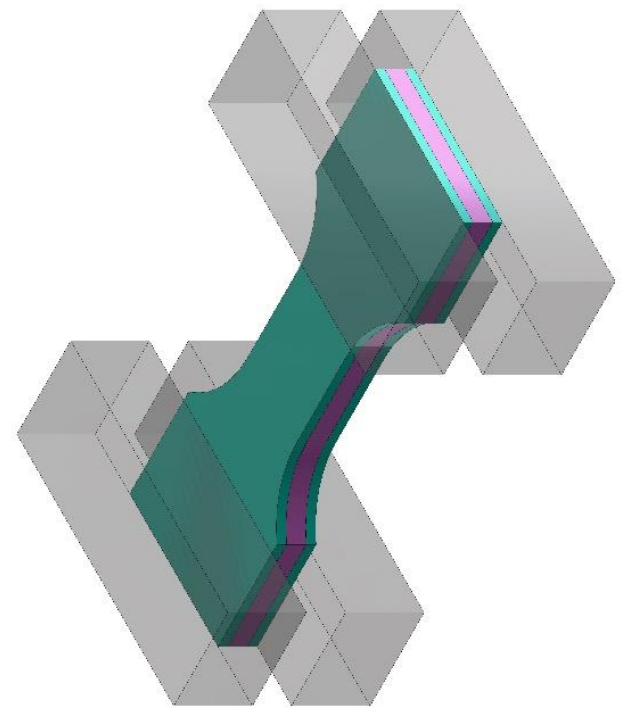

(b) 
122 Figure 2. Cross-ply laminate specimen designs: (a) rectangular (CP Cub), (b) clamped dog-bone $123(C P D B C)$.

124 Finally, a series of off-axis CP specimens were cut at orientations of 3, 6, 10 and $15^{\circ}$. These tests 125 were used to study the effects of combined in-plane shear and longitudinal compression on the fibre 126 strength and evaluate available fibre kinking failure theories. Similar to the standard $\pm 45^{\circ}$ tension 127 tests used to characterise the in-plane shear behaviour of composite laminates [13], the global 128 response of the laminate can be considered as a superposition of its constituent plies following CLT 129 only while there is no significant damage. The latter can cause considerable fibre rotation as well as 130 inter and intra-laminar softening, making it difficult to decouple the behaviour of individual plies 131 from the whole. Therefore, with these off-axis tests, a range of validity for the use of CP specimens 132 in combined longitudinal compression and shear was determined. If the validity of this approach can 133 be confirmed, the testing of compressive failure under combined loading would be greatly simplified 134 in comparison to the $\pm 5, \pm 10^{\circ}$ laminates and tube specimens used in the past $[14,15]$.

\section{$135 \quad 2.2 \quad$ Experimental setup and data process}

136 All the above experiments were conducted using a Zwick Roel $250 \mathrm{kN}$ universal screw-driven 137 testing machine under displacement control at a quasi-static loading rate of $0.01 \mathrm{~mm} / \mathrm{s}$. To ensure the 138 alignment of the loading plates and avoid any eccentricity, the load was applied through two bearing

139 balls an aligning frame, Figure 3, was installed. In addition, some cases required additional clamping 140 fixtures, which are also shown in Figure 3. 


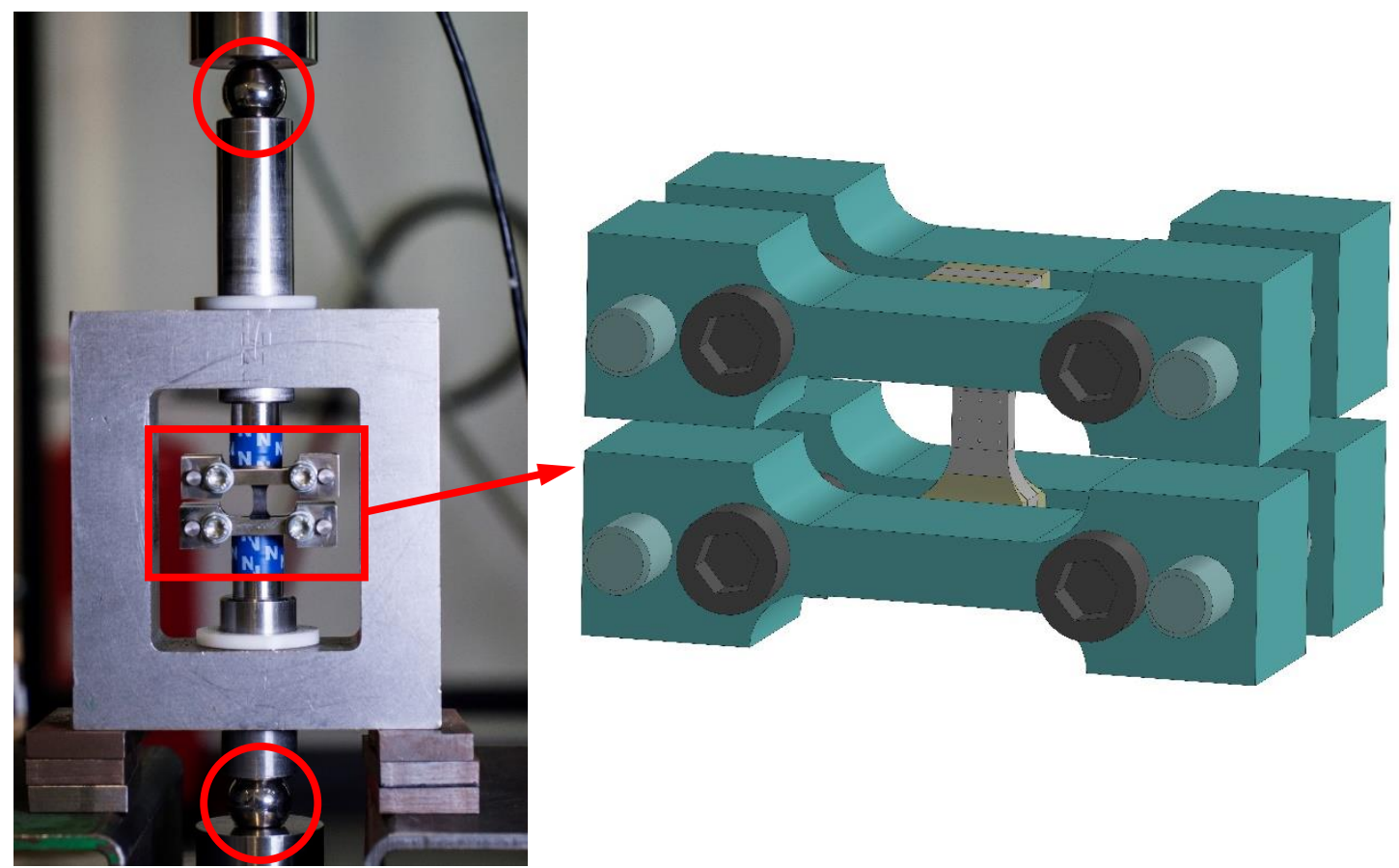

(a) Alignment fixture

(b) Specimen clamping fixtures

141 Figure 3. Alignment and clamping fixtures used in fibre compression tests. (a) bearing balls (circled)

142 and alignment frame set-up, which ensures a strictly axial load is applied to the specimens, (b) close-

143 up view of the compact clamping fixtures is shown.

144 Throughout the duration of the tests, force-displacement data was extracted at a $400 \mathrm{KHz}$ sampling

145 rate from the test rig. In order to capture the deformation of the specimens throughout the tests with

146 Digital Image Correlation (DIC) techniques, a digital camera was set to record one picture of 147 approximately $70 \times 120 \mathrm{~mm}$ at a 512x760px resolution every second. These images, along with finely 148 sprayed black and white speckle patterns on the surface of the specimens, allowed for the calculation 149 of full field strain histories, obtained by post-processing with the DIC analysis software GOM 150 Aramis.

151 Finally, in the case of CP specimens, as long as the assumptions of small strains and linear behaviour 152 were fulfilled, longitudinal compression strengths were extracted from the global laminate response 153 using CLT following the method described in section 2.1 [11]. 
154 In addition, following the experiments, a number of samples were selected for closer post-failure

155 analysis using optical microscopy (OM) and scanning electron microscopy (SEM).

\section{Experimental results}

157 For each of the three sets of experiments described in the previous section, stress-strain curves and 158 specimen strengths were extracted and are discussed below. The baseline strength measurements 159 from the UD test results are reviewed and discussed in section 3.1. Next, the comparison of the CP 160 results against the baseline UD measurements is shown to establish the equivalence between the two 161 in section 3.2. Finally, in section 3.3, the off-axis CP test results are analysed to determine a range of 162 validity of the CLT method for the determination of UD compression strength and the effects of 163 shear on this mode of failure are investigated.

\section{$164 \quad 3.1 \quad$ Unidirectional specimens}

165 Four different types of UD specimens were tested to study the effects of the boundary conditions and 166 obtain the most accurate strength measurement for this particular IM7-8552 material system and give 167 reference strength values for the rest of the study. These results are summarised in Figure 4 and

168 Figure 5, which show the evolution of stress vs strain and a comparison of ultimate axial strengths 169 between the different specimen designs, respectively. Since all specimens had the same stiffness, for 170 the sake of clarity, only the rectangular and clamped dog-bone (DBC) specimens, which showed the 171 minimum and maximum strength values, are shown in Figure 4. For the full comparison, the reader 172 is referred to

173 Figure 5 and Table 1 where all the ultimate strength results of all four types of specimens can be

174 found. Unfortunately, due to the shape of the fixtures and clamps, only the front, or in-plane surface 175 was visible for all specimens so that there was no way to monitor out of plane bending in the tests. 176 This may have been the cause for the significant scatter observed for some of the specimen designs 
177 and should be recorded, when possible. However, it should be noted that the selected cross-ply 178 designs showed good repeatability, as discussed in section 3.3.

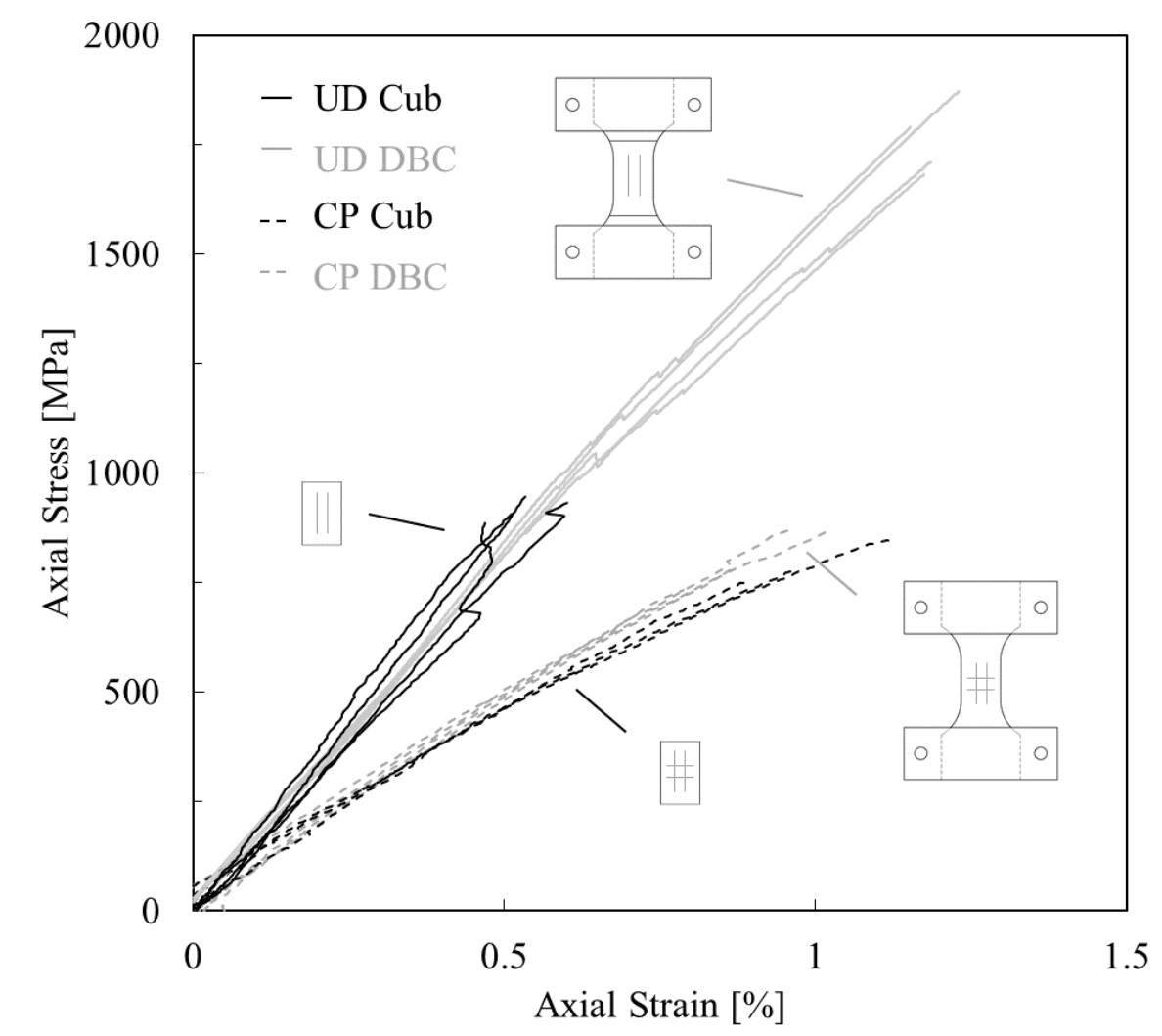

180 Figure 4. Comparison between $U D(D B C, C u b)$ and $C P$ specimens $(D B C, C u b)$ axial stress-strain 181 curves. 


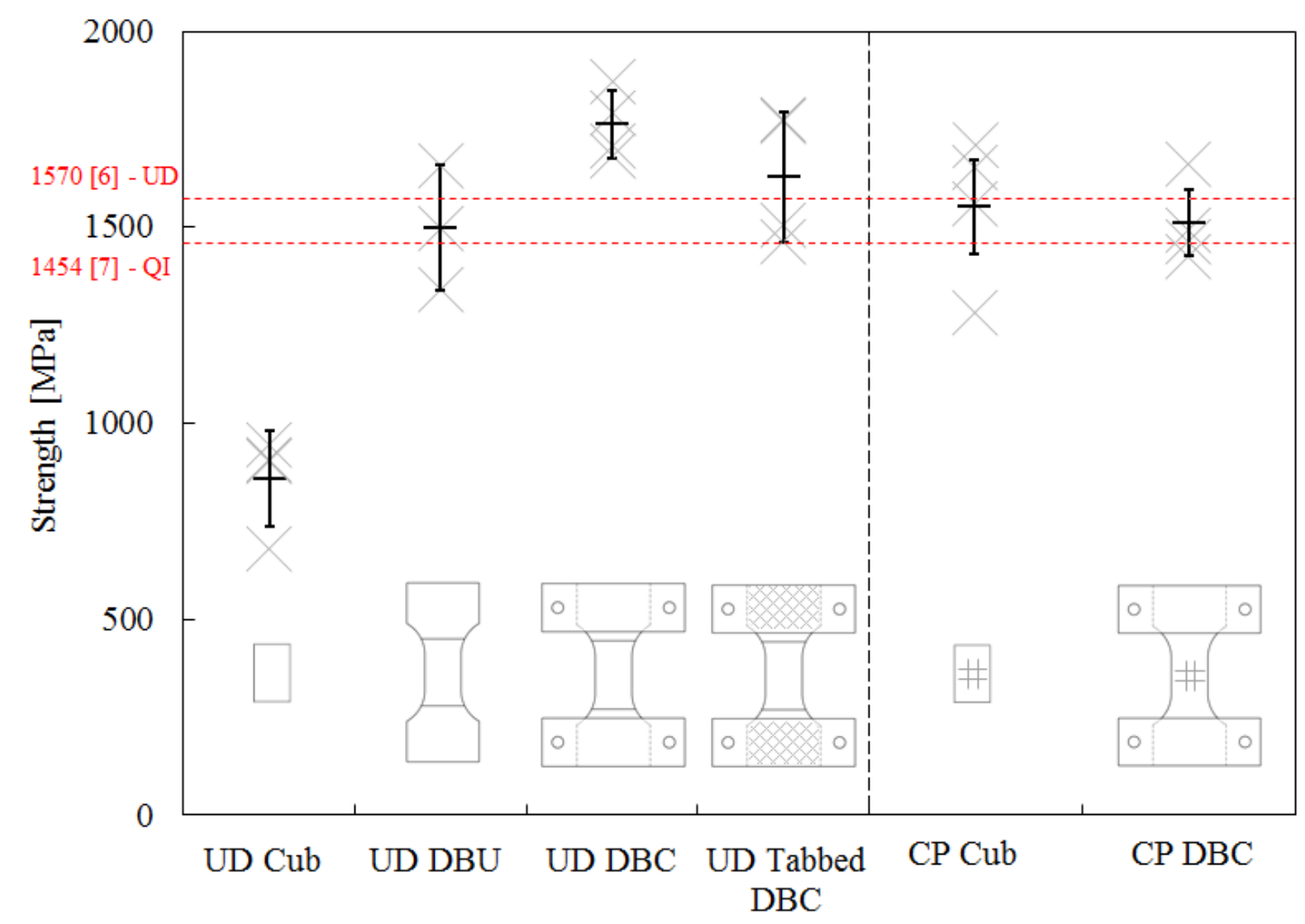

182

183 Figure 5. Axial strength comparison between the four tested UD specimen designs (Cub, DBU, DBC 184 and Tabbed DBC) and two CP specimen designs (Cub and DBC) with literature data from IM7-8552 185 UD and QI specimens [6,7] added for reference. Black cross-marks in the figure represent the mean 186 and standard deviation for each specimen type.

187 Table 1. Summary of $U D(C u b, D B U, D B C$ and Tabbed $D B C)$ and $C P(C u b, D B C) 0^{\circ}$ compression 188 test results. The asterisk marks a specimen that may have failed early due to stress concentrations at 189 the boundary.

\begin{tabular}{ccccc|cc}
\hline $\begin{array}{c}\text { Axial } \\
\text { Strength }\end{array}$ & $\begin{array}{c}\text { UD Cub } \\
{[\mathbf{M P a}]}\end{array}$ & $\begin{array}{c}\text { UD DBU } \\
{[\mathbf{M P a}]}\end{array}$ & $\begin{array}{c}\text { UD DBC } \\
{[\mathbf{M P a}]}\end{array}$ & $\begin{array}{c}\text { UD Tabbed } \\
\text { DBC }[\mathbf{M P a}]\end{array}$ & $\begin{array}{c}\text { CP Cub } \\
{[\mathbf{M P a}]}\end{array}$ & $\begin{array}{c}\text { CP DBC } \\
{[\mathbf{M P a}]}\end{array}$ \\
\hline $\mathbf{1}$ & 679 & 1499 & 1873 & 1773 & $1283^{*}$ & 1661 \\
$\mathbf{2}$ & 903 & 1340 & 1790 & 1506 & 1651 & 1423 \\
$\mathbf{3}$ & 945 & 1659 & 1710 & 1772 & 1558 & 1463 \\
$\mathbf{4}$ & 907 & & 1683 & 1462 & 1710 & 1494 \\
$\mathbf{5}$ & & & & 1381 & & \\
\hline AVG & 859 & 1499 & 1764 & 1579 & 1551 & 1510
\end{tabular}




\begin{tabular}{ccccc|cc} 
STDV & 121.2 & 159.5 & 85.6 & 182.6 & 189.2 & 104.6 \\
CV (\%) & 14.1 & 10.6 & 4.9 & 11.6 & 12.8 & 6.9 \\
\hline
\end{tabular}

191 As expected, the unclamped rectangular samples failed far below the expected fibre kinking strength 192 (1570 MPa) [6], at around $858 \mathrm{MPa}$ on average. The specimens failed catastrophically due to matrix

193 splitting that originated at the loading boundaries before fibre failure could occur (see Figure 6 (a)).

194 The unclamped dog-bone specimens (DBU), which tried to mitigate the effect of stress

195 concentrations at the loading edges, showed a considerable increase in strength, reaching $1499 \mathrm{MPa}$

196 on average, but still ultimately failed due to matrix splitting, as can be seen in Figure 6 (b).

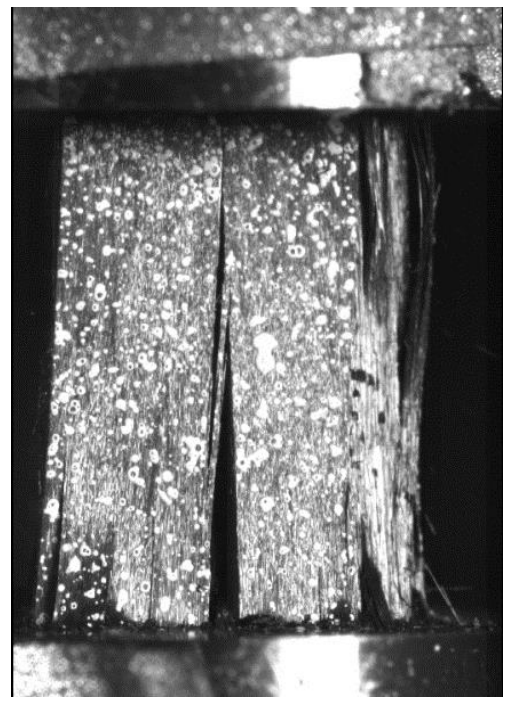

(a) $\mathrm{Cub}$

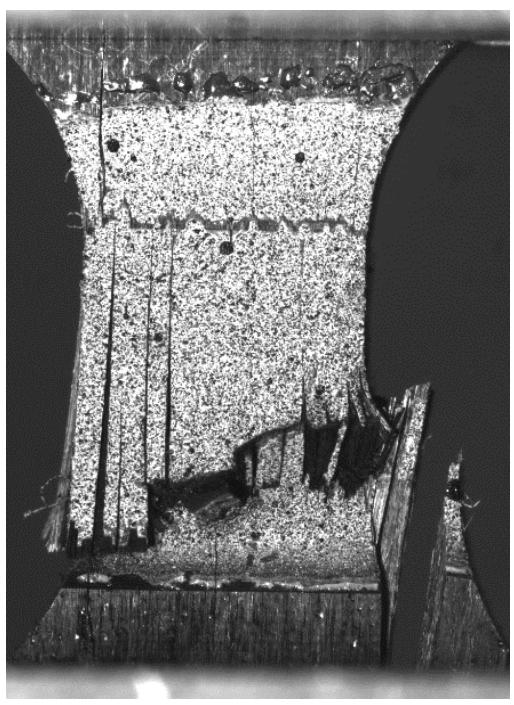

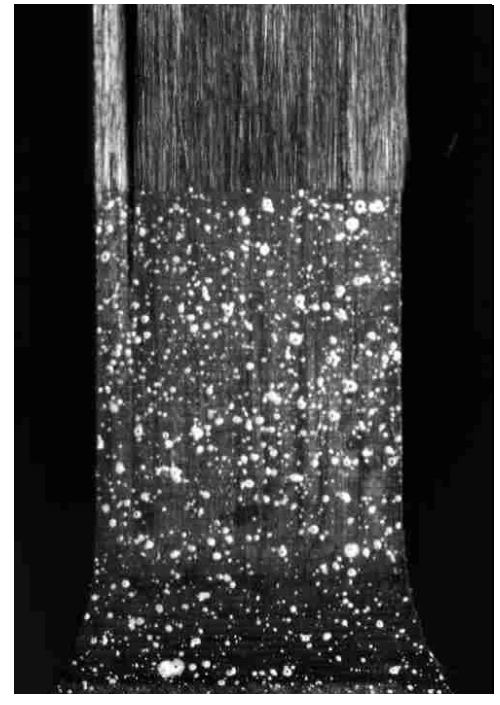

(b) DBU

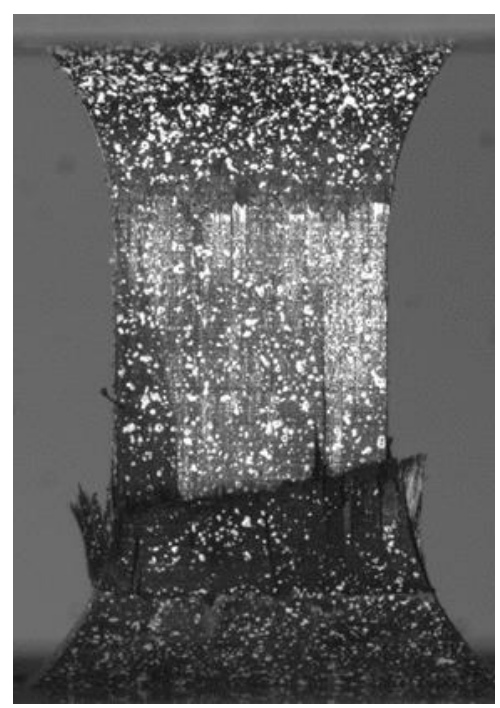




\section{$\begin{array}{ll}\text { (c) } \mathrm{DBC} & \text { (c) Tabbed DBC }\end{array}$}

197 Figure 6. Failed UD specimens showing different observed failure modes: (a) Cub, (b) DBU, (c)

198 DBC and $(d)$ Tabbed $D B C$.

199 Therefore, it was necessary to resort to clamping fixtures, as used in [6-8], to apply combined

200 loading compression (CLC, as described in ASTM D6641/D6641M) through combined end- and

201 shear-loading at the clamps and strengthen the matrix in the transverse direction. However, the cited

202 studies both reported kinking failure originating at the fixtures, likely caused by stress concentrations

203 from the abrupt change in boundary conditions. The clamping fixtures were, therefore, used in

204 combination with the dog-bone shaped specimens to reduce the effect of stress concentrations. Two

205 different types of clamped specimen were tested, the simple dog-bone specimens (UD DBC), and the

206 tabbed DBC specimens that included a layer of GFRP adhesively bonded to the composite below the

207 clamped surface.

208 Even in the DBC specimens, some matrix cracking, as occurred in the DBU specimens, could not be 209 completely prevented. However, in this case it only resulted in minor dips on the stress-strain curve,

210 highlighted on the DBC curves in Figure 4, and did not significantly affect the stiffness, indicating

211 that the load carrying ability was not affected. The DBC specimens continued to carry compressive

212 loads far beyond this intermediate matrix splitting and eventually failed as desired in the form of

213 kink bands within the gauge section, shown in Figure 6 (c), with an average strength of 1764 MPa.

214 On the other hand, the tabbed DBC specimen design was included to try and prevent the matrix 215 splitting observed at the dog-bone radius in some of the DBC specimens. In addition, the direct 
application of compressive fixtures could over-constrain the material and affect the fibre kinking

217 strength, dominated by localised matrix damage, which itself is strongly pressure-dependent [16-18].

218 Therefore, by relaxing the constraint on the UD material with the intermediate layer of GFRP

219 between the fixtures, some insight could be gained into the effects of boundary conditions on this

220 type of failure.

221 The tabbed DBC specimens failed at a much lower $1579 \mathrm{MPa}$ on average but, interestingly, the 222 results appeared to fall into two groups based on their failure stress and observed damage mode, 223 although further testing would be required to verify this. One group of specimens failed below 1500

$224 \mathrm{MPa}$ with most specimens failing by matrix splitting as in the unclamped specimens and a couple of 225 cases of fibre kinking that initiated nearer to the boundary, possibly due to stress concentrations. The 226 second group failed at stress above 1700MPa, by kinking within the gauge section with no noticeable 227 matrix cracking (see Figure 6 (d)) and reached strengths very similar to the previous DBC specimen 228 design.

229 From these results, it appears that there are possibly two different failure modes under longitudinal 230 compression. For this specific IM7-8552 composite system, the combination of material properties 231 and fibre waviness are enough to cause matrix failure resulting in splitting and fraying at an axial 232 stress of around $1500 \mathrm{MPa}$, as observed in the unclamped DBU specimens and the first subgroup of 233 tabbed DBC specimens. However, the formation of kink bands did not occur until axial stress levels 234 between 1700-1800 MPa. It would seem that, for this fibre micro-buckling to occur, the material may 235 have to be over constrained to some degree, preventing matrix damage from resulting in splitting or 236 fraying, allowing the fibres to reach the higher buckling load.

\section{$237 \quad 3.2 \quad$ Cross-ply specimens}

238 In light of these issues with testing the thick UD specimens, a set of $\left[0^{\circ} / 90^{\circ}\right]_{4 s}$ cross-ply specimens 239 were tested following suggestions in the literature that multi-directional laminates may be better 
240 suited for the determination of fibre kinking strength $[6,7,11,19]$ as the transverse plies help to 241 reinforce the longitudinal fibres, allowing them to reach their buckling strength without the need for 242 additional external constraints.

243 For the cross-ply material, only two specimen designs were tested, an unclamped rectangular 244 specimen (CP Cub) and a clamped dog-bone specimen (CP DBC), shown in Figure 2. The results are 245 summarised in Table 1 and the axial stress-strain curves for both specimen types are shown in Figure 2464 and

247 Figure 5. These also show the geometries and the extracted longitudinal compression strength next to 248 the UD specimen results. Since the stress-strain curves in Figure 4 showed no noticeable nonlinearity 249 and there were no signs of damage or fibre rotation in the specimens before fracture was observed, 250 the use of linear CLT for the extraction of longitudinal ply properties [11] was considered valid and 251 the ply strength data given in Table 1 and

252 Figure 5 is used for the rest of the discussion below.

253 As expected, both (CP Cub and CP DBC) geometries presented similar axial stiffness and practically 254 the same axial strength, with the Cub specimen showing slightly greater scatter. In addition, both 255 specimens failed within the gauge section, see Figure 7, due to fibre kinking originating in the central 256 plies and propagating outwards. Unfortunately, because of this, no particularly useful failure images 257 were captured on the outer layers during the test. However, section 4 includes more detailed 258 microscopy images of different off-axis specimens showing typical failure propagation through 259 longitudinal and transversal plies in CP specimens. 


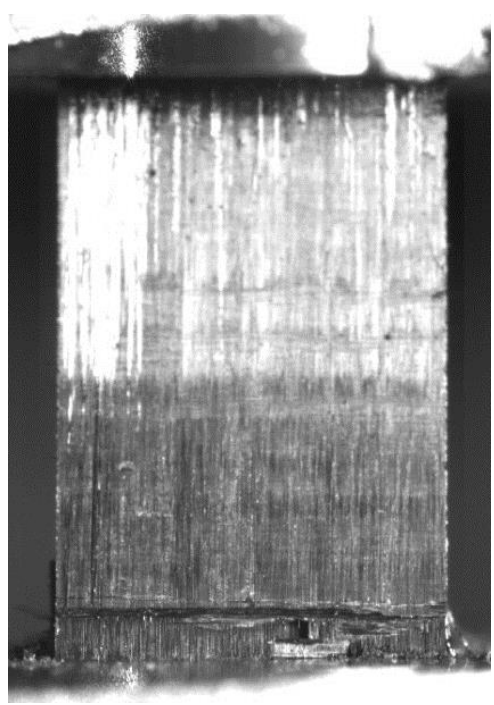

(a) $\mathrm{Cub}$

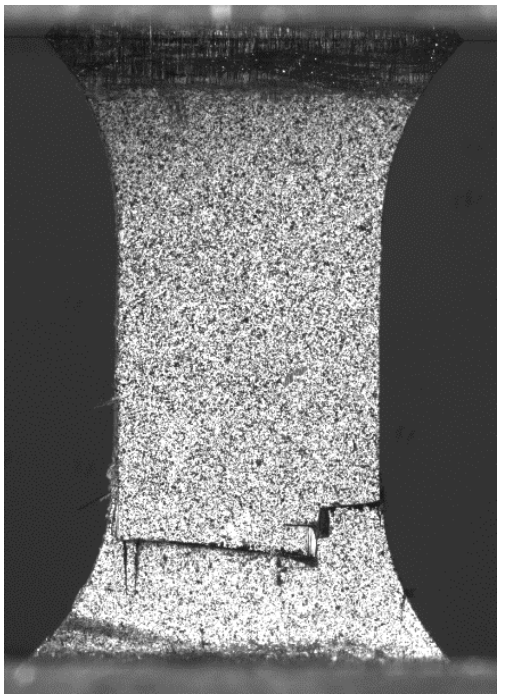

(b) DBC

260 Figure 7. Failed CP specimens showing failure on the outer plies after initiating and propagating 261 outwards through the laminate. Left to right: (a) CP Cub and (b) CP DBC specimens.

262 At a first glance, these results show that the practical issues encountered in testing the UD material 263 are in fact avoided when testing the CP laminates, as no complex specimen design or fixtures are 264 required to produce the desired mode of failure. In addition, the clamping fixtures did not appear to 265 affect the compressive strength, although they may have improved experimental scatter. As a side 266 note, however, significant experimental scatter is typically expected in this type of experiment due to 267 the nature of the failure mode, which is caused by local fibre misalignments that can vary from one 268 specimen to another. For reference, both the UD tests and the data from clamped QI specimens in $269[6,7]$ showed a similar variation in strength measurements.

270 However, when compared to the UD results from section 3.1, there are noticeable differences. Both $271 \mathrm{CP}$ specimens (CP $\mathrm{Cub}$ at $1551 \mathrm{MPa}$ and $\mathrm{CP} \mathrm{DBC}$ at $1510 \mathrm{MPa}$ ) failed at similar equivalent 272 longitudinal ply strengths to the unclamped DBU and the subset of tabbed DBC specimens that 273 failed due to matrix splitting. The UD specimens that reached fibre kinking strength, on the other 274 hand, failed at around 1700 to $1800 \mathrm{MPa}$. 
275 Previous studies on the same material showed longitudinal strength in QI laminates similar to that 276 obtained here in the CP material and UD strength 10-20\% lower [6,7]. However, UD specimens in 277 both were reported to fail at the clamp edges, indicating that they may have suffered from critical 278 stress concentrations, causing local matrix damage and premature onset of fibre kinking failure.

279 As discussed in the previous section, for the UD material it can be assumed that the material 280 properties and local fibre misalignment (typically up to $3^{\circ}$ [20]) result in the onset of Inter Fibre 281 Failure (IFF) damage at longitudinal compressive loads of around $1500 \mathrm{MPa}$ and the fibre micro282 buckling strength, between 1700 and $1800 \mathrm{MPa}$, is only reached with sufficient additional constraints 283 on the longitudinal fibres to make up for the reduced matrix support.

284 If similar material properties and fibre waviness to the UD laminate are assumed, it would seem that 285 multi-directional laminates tend to fail at the onset of matrix damage, similar to the unconstrained 286 UD specimens, whereas the stronger constraints on clamped UD specimens allows further matrix 287 damage evolution and greater compressive loads before the constrained fibre buckling strength is 288 reached.

289 Therefore, CP or other multi-directional laminates can be used to measure the longitudinal 290 compression strength more reliably than UD material and without the need for complicated fixtures. 291 In addition, if the objective is to characterise the behaviour of UD plies in a multidirectional 292 laminate, taking into consideration possible size effects and differences in local fibre architecture 293 such as those noted by Lee and Soutis [6], it may be argued that CP specimens will give a more 294 representative measurement of the expected compressive strength. In fact, unidirectional material 295 should be used with extreme caution as the material strength can very easily be under- or 296 overestimated. Without the use of clamping fixtures, stress concentrations and edge effects can 297 prematurely initiate matrix cracking and even fibre kinking as observed in the unclamped specimens 298 in section 3.1 and in [6,7]. At the same time, the clamping fixtures can over constrain the material 
299 and delay the onset of fibre buckling, resulting in greater observed ultimate strength than would be 300 possible otherwise.

\section{$301 \quad 3.3 \quad$ Off-axis compression specimens}

302 Having established the use of $\mathrm{CP}$ specimens for the measurement of the UD ply longitudinal 303 compression strength, a set of off-axis compression tests were carried out to determine range of

304 validity in combined loading, which is critical for the evaluation of 3D failure kinking theories. A 305 series of CP Cub samples cut at $0,3,6,10$ and $15^{\circ}$ with respect to surface fibre direction were tested 306 in the same manner as the uniaxial compression test in section 3.2.

307 While the same was attempted for UD DBC and CP DBC specimen designs, these presented several 308 issues that made the data unreliable. In both cases, the waisted design of the specimens in 309 combination with the slight misalignment of the fibres, resulted in a non-uniform strain distribution 310 through the gauge section and stress concentrations at the change in section were greatly exaggerated 311 in the off-axis specimens, see Figure 8 (b). Because of this, it was difficult to accurately determine 312 the stress state at the point of failure and, therefore, directly extract a material property from the axial 313 measurements. In addition, in UD specimens, the same off-axis angles resulted in much greater shear 314 stresses, producing significant fibre rotation and changes in the failure mode from fibre buckling to 315 matrix dominated shear banding. 


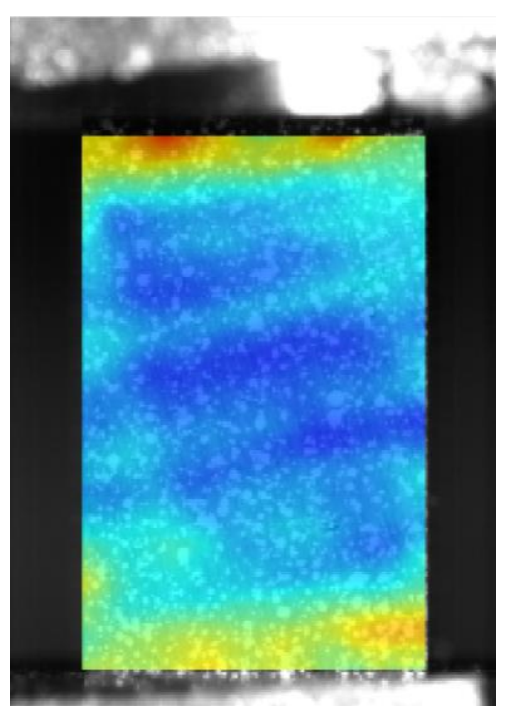

(a) $\mathrm{CP} \mathrm{Cub}$

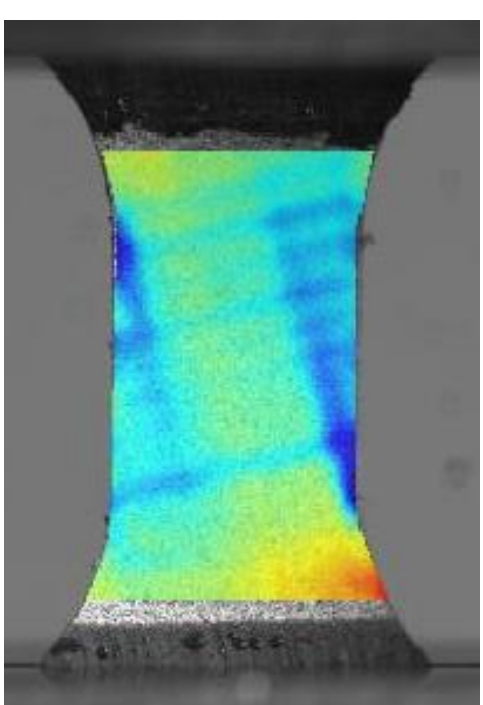

$\varepsilon_{y y}[\%]$

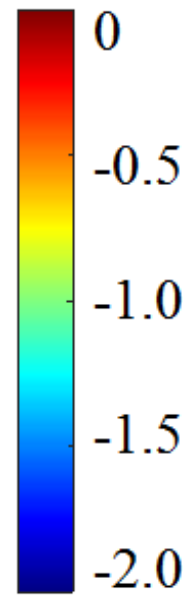

(b) CP DBC

316 Figure 8. DIC longitudinal strain $\left(\varepsilon_{y y}\right)$ overlay on two specimens showing non-uniform distribution in

317 a $15^{\circ}$ off-axis $C P$ DBC (b) compared to a $15^{\circ}$ Cub specimen (a).

318 In contrast, the rectangular CP specimens (see Figure 8 (a)) showed a much more uniform strain

319 distribution throughout the gauge section, which allowed for average axial stresses to be used more

320 reliably to extract individual ply stress states and ultimate strength measurements. Therefore, only

321 these were used in the off-axis compression study.

322 The axial data obtained for the off-axis CP Cub specimens is summarized in Table 2 and Figure 9,

323 which give the axial strength data and stress strain curves, respectively. A decrease in strength can be

324 observed as the off-axis angle increases, with noticeable nonlinearity in all specimens beyond $6^{\circ}$,

325 which also showed significant fibre rotation as the experiments progressed.

326 Table 2. Summary of off-axis $\left(0,3,6,10\right.$ and $\left.15^{\circ}\right) C P C u b$ axial strength results.

\begin{tabular}{cccccc}
\hline $\begin{array}{c}\text { Axial } \\
\text { Strength }\end{array}$ & $\begin{array}{c}\mathbf{C P ~ C u b ~ 0}^{\circ} \\
{[\mathbf{M P a}]}\end{array}$ & $\begin{array}{c}\mathbf{C P ~ C u b ~ 3}^{\circ} \\
{[\mathbf{M P a}]}\end{array}$ & $\begin{array}{c}\mathbf{C P ~ C u b ~ 6}^{\circ} \\
{[\mathbf{M P a}]}\end{array}$ & $\begin{array}{c}\mathbf{C P ~ C u b ~ 1 0}^{\circ} \\
{[\mathbf{M P a}]}\end{array}$ & $\begin{array}{c}\mathbf{C P ~ C u b ~ 1 5}^{\circ} \\
{[\mathbf{M P a}]}\end{array}$ \\
\hline $\mathbf{1}$ & 747 & 744 & 623 & 467 & 341 \\
$\mathbf{2}$ & 783 & 746 & 643 & 468 & 353 \\
$\mathbf{3}$ & 847 & 741 & 706 & 452 & 353 \\
$\mathbf{4}$ & & & 630 & 451 & 350
\end{tabular}




\begin{tabular}{cccccc}
$\mathbf{5}$ & & & & 466 & 363 \\
\hline AVG & 792 & 744 & 651 & 461 & 352 \\
STDV & 50.6 & 2.1 & 37.9 & 8.5 & 7.9 \\
CV $(\%)$ & 6.4 & 0.3 & 5.8 & 1.9 & 2.3 \\
\hline
\end{tabular}

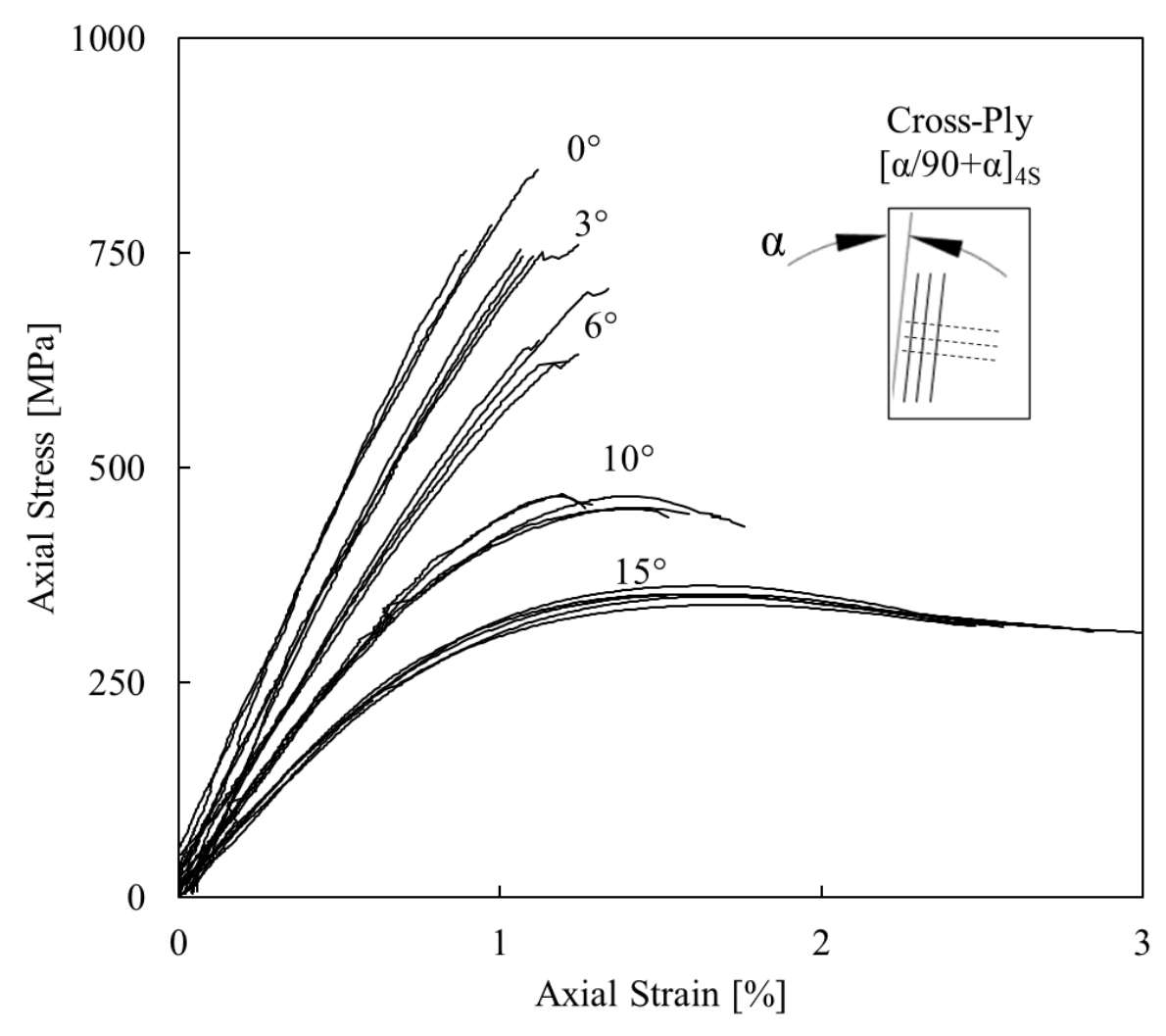

329 Figure 9. Comparison of axial stress-strain curves for CP specimens with misalignment angles of 0 , $3303,6,10$ and $15^{\circ}$.

331 For a more in-depth look, macroscopic and SEM images in Figure 10 show the observed signs of 332 fibre kinking failure in longitudinal plies and help to illustrate the differences in modes of failure 333 between $3^{\circ}, 6^{\circ}$ and $10^{\circ}$ specimens. For the lower off-axis specimens, from 0 to $6^{\circ}$, failure appeared 334 to originate in the central longitudinal plies and propagate outwards, with the fibres tending to buckle 335 in the out-of-plane direction. Conversely, for the 10 and $15^{\circ}$ specimens, ultimate failure was 336 preceded by significant shear non-linearity, which seemed to promote buckling in the same direction, 337 keeping it more contained within the plane. 


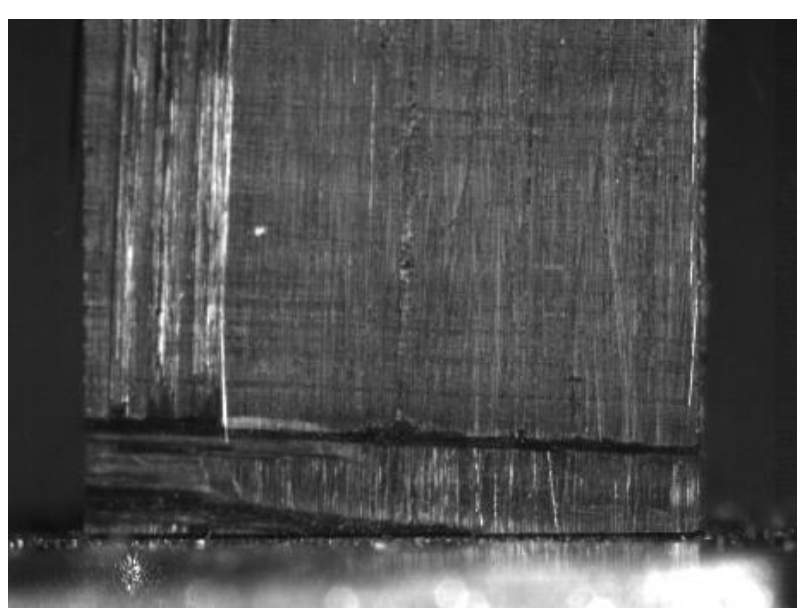

(a) $3^{\circ} \mathrm{CP}$ - failure surface

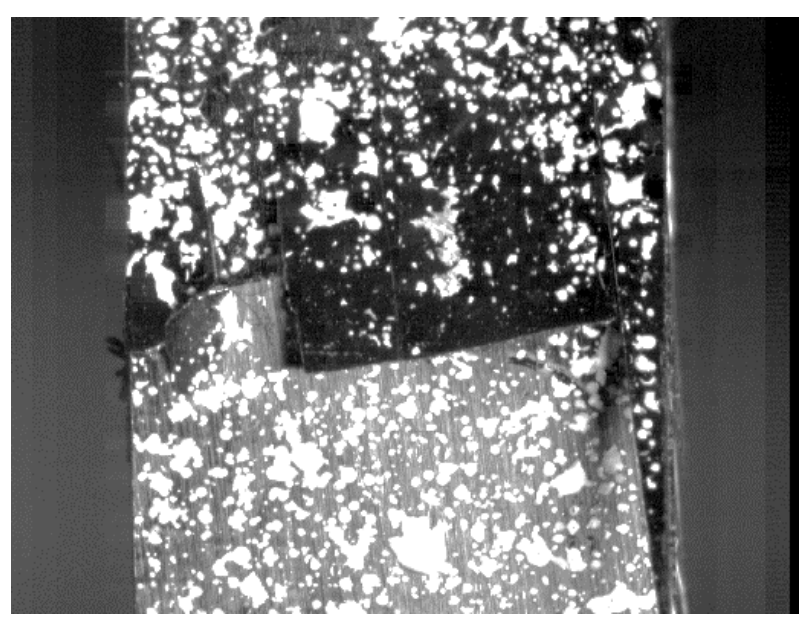

(c) $6^{\circ} \mathrm{CP}$ - failure surface

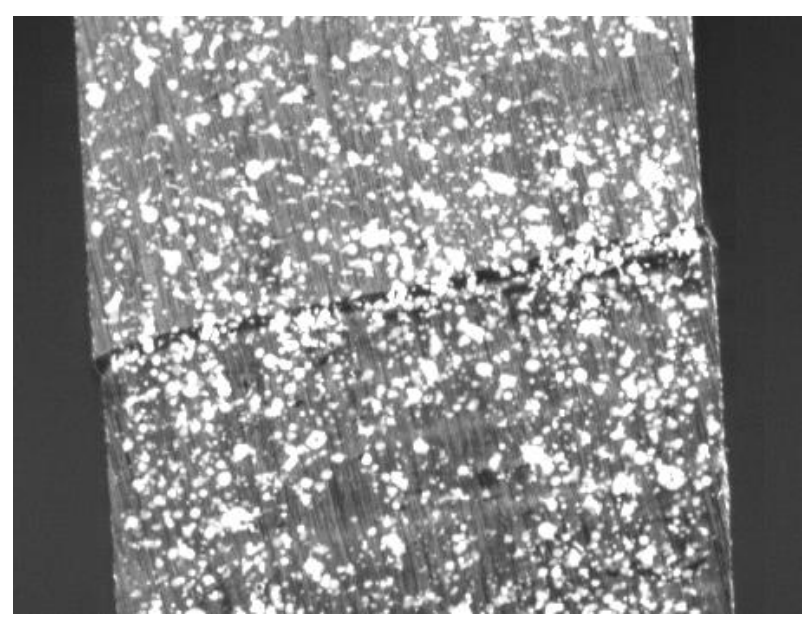

(e) $10^{\circ} \mathrm{CP}$ - failure surface

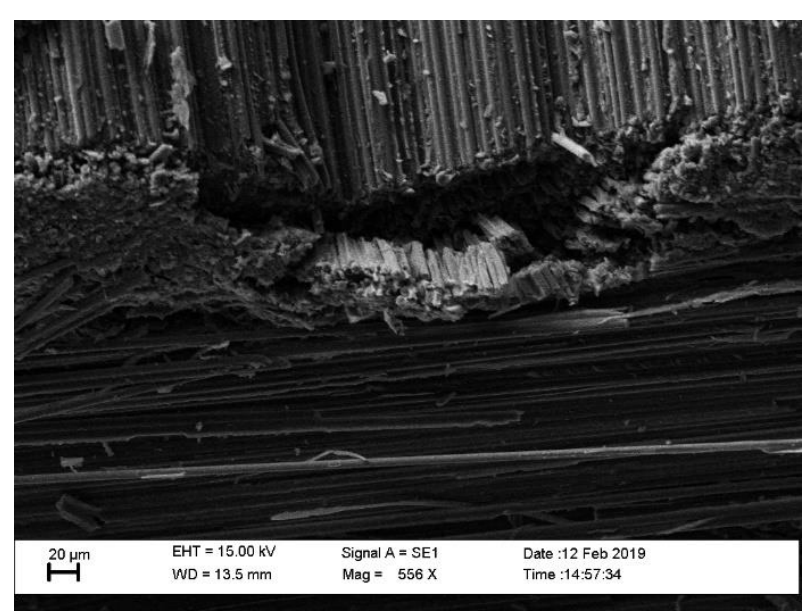

(b) $3^{\circ} \mathrm{CP}$ - through thickness SEM

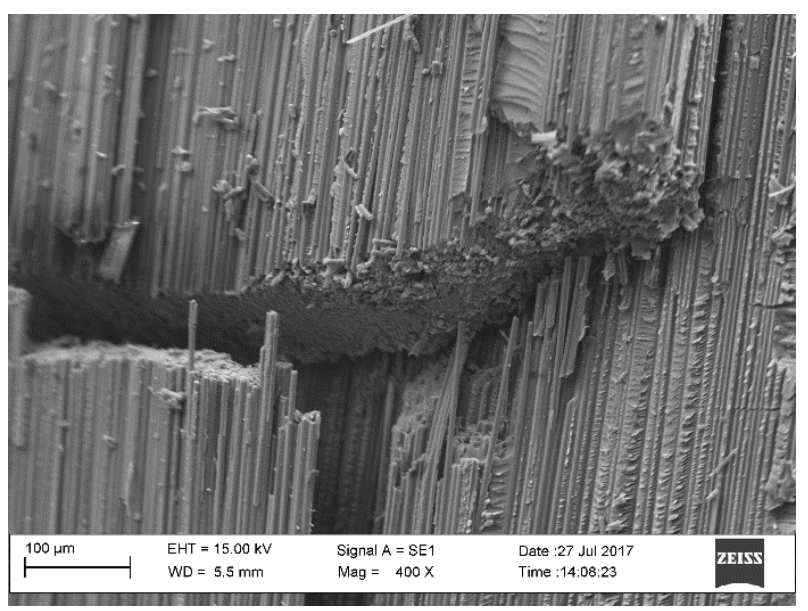

(d) $6^{\circ} \mathrm{CP}$ - through thickness SEM

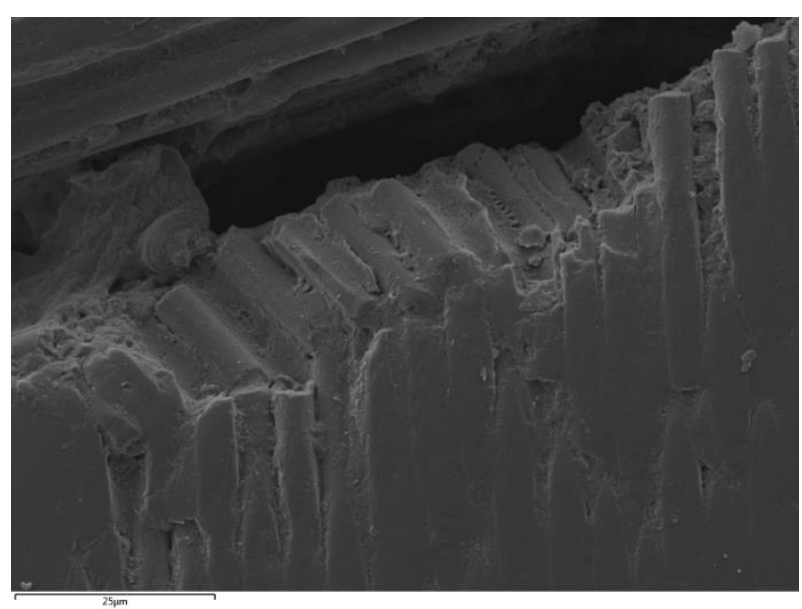

(f) $10^{\circ} \mathrm{CP}$ - through thickness SEM

338 Figure 10. Macroscopic (digital camera) and Scanning Electron Microscope (SEM) images of

339 different failed 3, 6 and $10^{\circ} \mathrm{CP}$ specimens showing signs of fibre kinking failure. Scale bars indicate

$34020 \mu \mathrm{m}$ in (b), $100 \mu \mathrm{m}$ in $(d)$, and $25 \mu \mathrm{m}$ in $(f)$. 
341 Up to $6^{\circ}$, however, there was no noticeable nonlinearity and no signs of damage or fibre rotation in

342 the specimens before the point of failure. In addition, shear stress-strain curves for the same IM7-

3438552 material in [21,22] show significant nonlinearity starting only after shear stresses of around 60-

$34470 \mathrm{MPa}$ and both the 3 and $6^{\circ}$ tests fall below that limit (see Figure 11). Therefore, for these

345 specimens, an accurate estimate of the internal stress state in the longitudinal plies can be obtained

346 using linear CLT, as was done for the uniaxial compression tests in section 3.2, and the use of CP

347 material instead of UD can be considered valid.

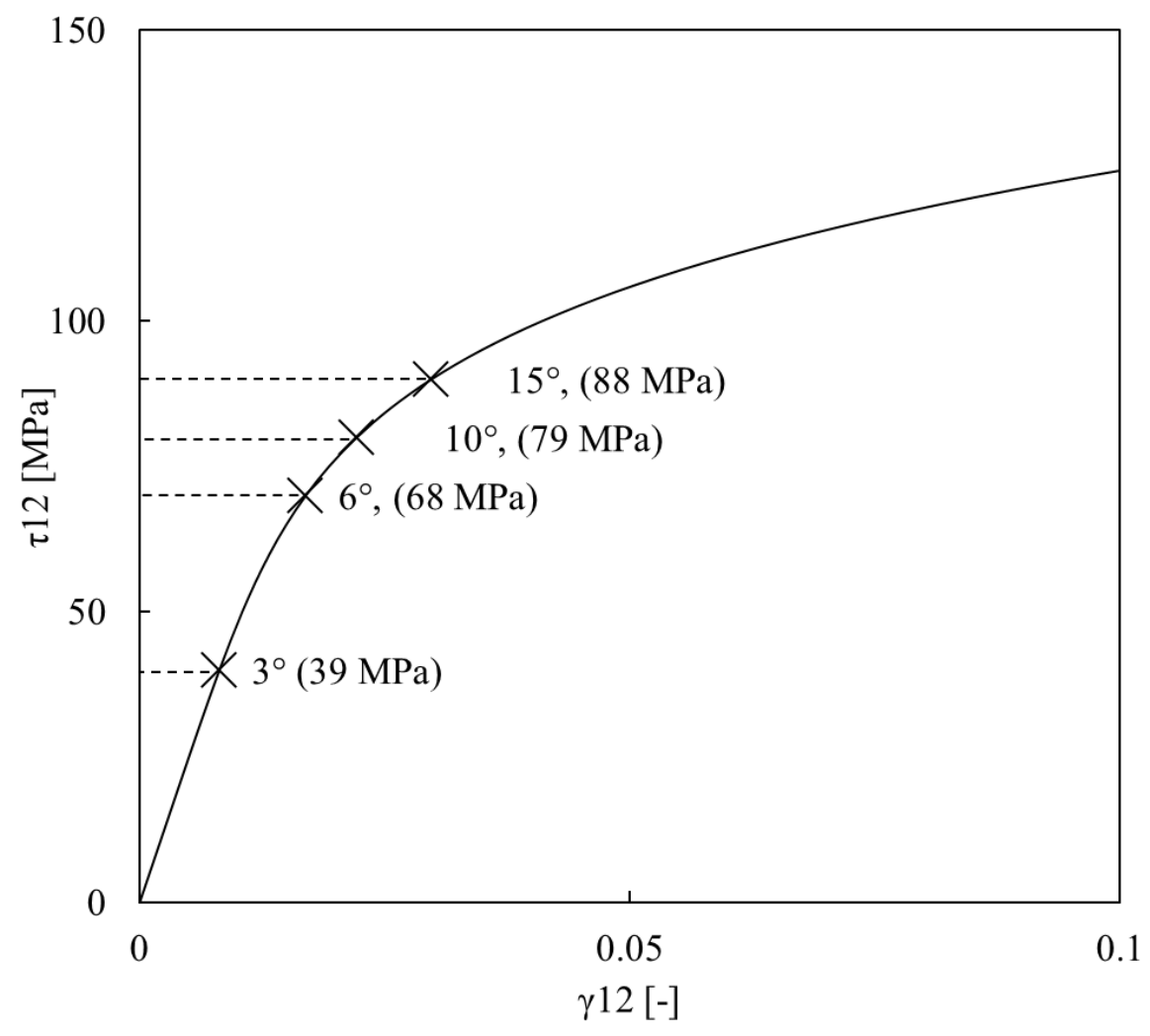

349 Figure 11. Average shear stresses from the 3 and $6^{\circ}$ off-axis compression tests overlaid on the 350 experimental shear stress-strain curve for an IM7-8552 composite, reproduced from [22].

\section{Discussion and analysis}

352 Based on all the results gathered above, simple CP specimens can be used to determine the 353 longitudinal compression strength of unidirectional composite material in both uniaxial and off-axis 
354 compression tests, without the need for complex fixtures, for as long as the stress-strain curves 355 remain linear. In this case, for the IM7-8552 composite, this limit was found at around $6^{\circ}$ when the 356 shear stresses in the laminate reached around 60-70 MPa. For greater off-axis angles, useful data 357 cannot be simply extracted using linear CLT and a more rigorous analysis would be required, giving 358 consideration to the nonlinear behaviour of the material, possible interlaminar damage, and fibre or 359 specimen rotation.

360 For the uniaxial compression case, various different UD specimen designs were tested to obtain a 361 reliable reference measure of the material's compressive strength. From these tests a serious 362 difficulty in reaching the desired fibre micro-buckling failure mode was noted. Firstly, waisted, or 363 dog-bone, specimen designs were necessary to avoid stress concentrations at the edges causing 364 premature failure.

365 However, even then, there appear to be two different mechanisms dictating the compressive strength 366 of the material depending on the boundary conditions of the experiment. For tests with more relaxed 367 lateral constraints, including completely unclamped and clamped specimens with GFRP end tabs 368 between the clamping fixtures, the material tended to fail due to matrix cracking and fibre kinking 369 was rarely produced. On the other hand, fibre kinking, or micro-buckling, failure was only 370 consistently achieved when the specimens were over-constrained, with the clamping fixtures 371 possibly maintaining alignment of the fibres beyond the IFF failure of the matrix. Between these two 372 different scenarios, matrix failure measured at around $1500 \mathrm{MPa}$, while the over-constrained fibre 373 kinking mode was measured at over 1700 to $1800 \mathrm{MPa}$.

374 From this it was concluded that: (i) reliable compression strength measurements were extremely 375 difficult to achieve with UD material; and (ii) the compressive failure of the laminate was caused by 376 failure of the supporting matrix, at around $1500 \mathrm{MPa}$. 
377 In second place, two different CP specimen designs were tested to compare against the UD results, a 378 rectangular unclamped specimen and a clamped dog-bone design. The two different specimens 379 showed no significant differences between them, regardless of shape or the use of clamping fixtures, 380 indicating reliable material and test design. Not only that, but the extracted longitudinal compression 381 strength using CLT [11] coincided with the measured UD results at $1500 \mathrm{MPa}$. Therefore, CP 382 laminates have been shown to produce accurate results for longitudinal compressive strength and, 383 due to greater reliability and lower sensitivity to boundary conditions, it is strongly recommended to 384 use this type of material over UD laminates. In addition, fibre kinking strength is dependent on local 385 fibre architecture and, therefore, a cross-ply, or quasi-isotropic, layup will better characterize the 386 behaviour of multi-directional laminates, which are more typically used in engineering applications.

387 Finally, for the case of off-axis compression, the same CP material was used to prepare angled 388 specimens cut at $0,3,6,10$ and $15^{\circ}$ from the fibre direction. These showed that, as long as the 389 resultant stress-strain curves remained linear, the assumptions of CLT remained valid and the effects 390 of combined loading on the compressive strength could be measured the same specimen/test design 391 as the previous uniaxial compression tests.

392 Shuart et al. in 1989 and Soden et al. in 2002 used \pm 5 and $\pm 10^{\circ}$ angle-ply specimens and 393 unidirectional tubes, respectively, to study the longitudinal compressive strength of fibre composites 394 under combined loading $[14,15]$. The effects of shear on longitudinal compression strength observed 395 in the present study follow a similar trend to the results from [14,15], shown normalised against the 396 uniaxial compression strength for each material in Figure 12 for a clearer comparison, which adds 397 confidence in the validity of the proposed specimen design. In addition, the CP specimen presents 398 several advantages over previous approaches: the CP material is more readily available and multiple 399 different orientations can be obtained from a single laminate, making it a more versatile, cost400 effective and convenient method to test different shear-longitudinal compression ratios. 


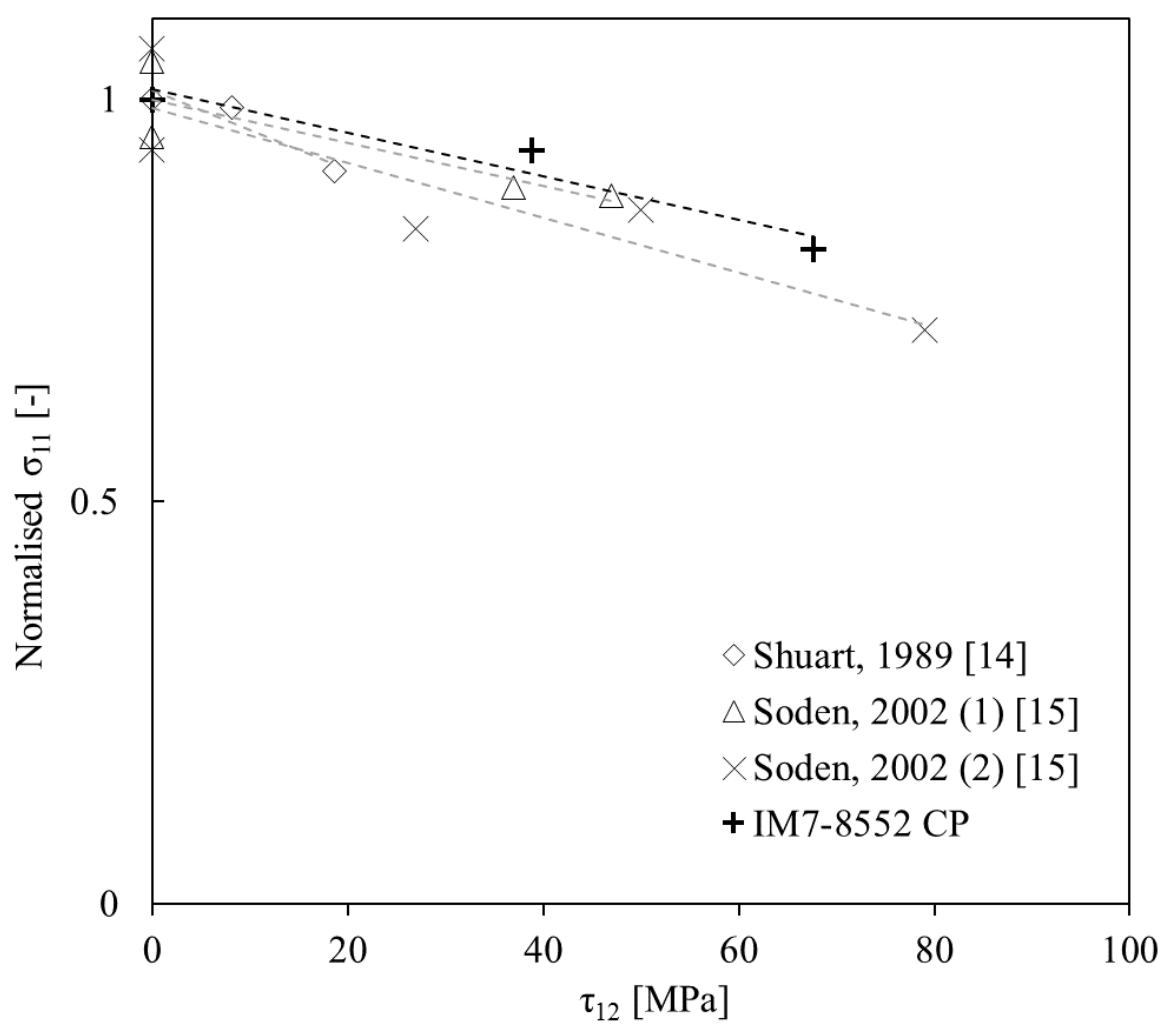

402 Figure 12. Comparison of combined longitudinal compression and in-plane shear test results

403 between different materials and test methods in the literature $[14,15]$ and the new results presented 404 in this article. Two different data sets from [15] are included. Results are shown normalised with the 405 uniaxial compression strength for each material.

406 Finally, the obtained results were used to evaluate the fibre kinking theory proposed by Pinho in [5], 407 which is one of the few criteria for this type of failure with a sound physical explanation 408 implemented in three dimensions and has been shown to produce good results in the uniaxial 409 compression case [23]. This theory consists in rotating the macroscopic stress state to an internal 410 misalignment frame, Figure 13 (a), obtained by adding the local shear strain to the initial fibre 411 waviness.

412

$$
\boldsymbol{\sigma}^{m}=\mathbf{R}[\varphi] \boldsymbol{\sigma}^{\psi}
$$

$$
\varphi=\operatorname{sign}\left[\tau_{12}^{\psi}\right] \varphi^{0}+\gamma_{m}
$$


414 Where $\varphi$ is the misalignment angle, $\varphi^{0}$ is the initial misalignment, and $\gamma_{m}$ is the shear strain in the

415 misalignment frame. The kink-band stress, $\boldsymbol{\sigma}^{\psi}=\mathbf{R}[\psi] \boldsymbol{\sigma}$, is obtained in a similar manner by rotating

416 the Cauchy stress vector, $\sigma$, to the kink-band plane with the angle, $\psi$, found numerically.

417 The local misalignment frame stresses are then used to evaluate the fibre finking criterion, where

418 failure can occur by instability of the additional fibre rotation, if $\gamma_{m}$, which is solved iteratively, does

419 not have a stable solution, or by matrix fracture, if $\gamma_{m}$ is stable and:

$420 \quad f_{\text {kink }}=f_{\mathrm{IFF}}\left[\boldsymbol{\sigma}^{m}\right]=1$

421 Where the kinking criterion, $f_{\text {kink }}$, is evaluated as an IFF criterion of the type described in $[4,5,24]$

422 on the misalignment frame, $f_{\mathrm{IFF}}\left[\sigma^{m}\right]$. A more detailed explanation and subsequent simplifications

423 made over the years to avoid iteration can be found in [3-5], however only the original, numerically

424 intensive, implementation has been used here to prevent any possible loss of accuracy.

425 When used to study the present off-axis CP experiments, however, this theory, as originally 426 described in [25], appears to over predict the effect of shear. Predictions are shown next to 427 experimental results in terms of longitudinal $\left(\sigma_{11}\right)$ vs shear $\left(\tau_{12}\right)$ stress at failure in Figure 14.

428 However, with a minor modification, predictions can be greatly improved for cases with combined 429 shear. The proposed modification consists in replacing the misalignment frame shear strain, $\gamma_{m}$, from 430 (7) with a relative shear strain measure, $\gamma_{m}^{r}$, shown below.

$$
\gamma_{m}^{r}=f_{\mathrm{CL}}\left[\tau_{12}^{r}\right]=f_{\mathrm{CL}}\left[\tau_{12}^{m}-\tau_{12}^{\psi}\right]
$$

432 In an analogous way, $\gamma_{m}^{r}$ is obtained from the very same constitutive law $\left(f_{C L}\left[\tau_{12}^{r}\right]\right)$ employed 433 previously to calculate $\gamma_{m}$. However, now a relative shear stress, $\tau_{12}^{r}$, is used instead of $\tau_{12}^{m}$. In this 434 way, as the global fibre direction rotates with $\tau_{12}^{\psi}$, only the shear strain relative to the current material 435 orientation is considered for the misalignment angle calculation. Otherwise, the local fibre rotation is 
overestimated as illustrated in Figure 13 (b), where $\varphi$ is the misalignment angle computed per

437 Pinho's original implementation, while $\varphi^{*}$ is the angle corresponding to the proposed modification.

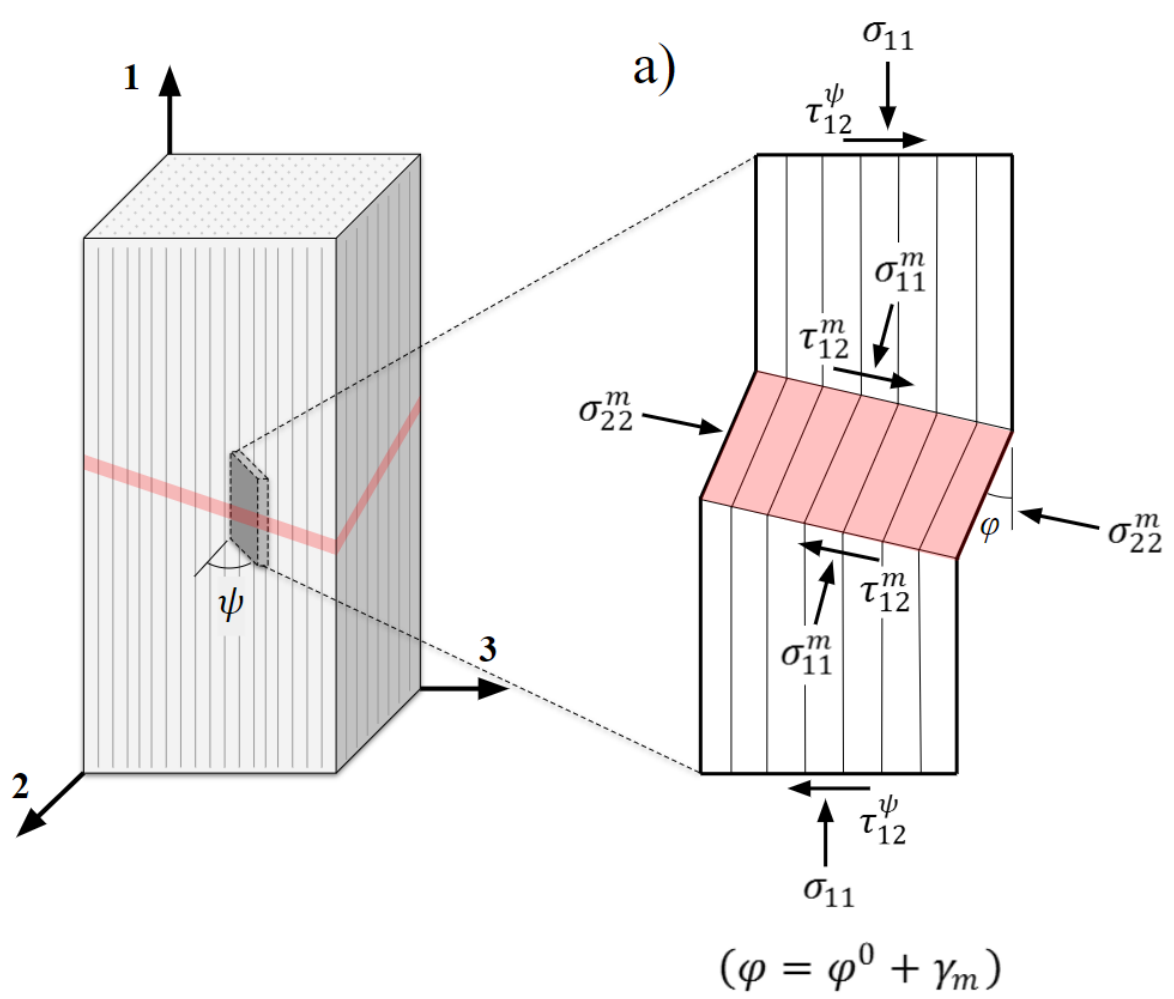

Figure 13. a) Kink-band and misalignment planes according to fibre kinking theory $[1,2,5]$ and b) effect of considering the proposed relative shear vs the global shear for the misalignment angle, $\varphi$.

441 Both models were calibrated with the average uniaxial compression strength and shear stress-strain 442 behaviour from [14,15] and gave an initial misalignment angle of $1.85^{\circ}$, which falls within typical 443 expected values and matches the analytical solution for the uniaxial compression case as described in 444 [26]. With the proposed modification, the solution remains unchanged for the pure compression case 445 but, for off-axis compression cases, there are some noticeable improvements. In the $0^{\circ}$ and $3^{\circ}$ tests, 446 the longitudinal compression strength $\left(\sigma_{11}\right)$ remains constant as the local shear stress in the 447 misalignment frame remains in the linear elastic region and buckling occurs purely due to 448 mechanical instability of the misaligned fibres. Beyond this point, the greater shear stresses cause 449 matrix failure in the local misalignment frame before the instability condition is met, with 450 subsequent micro-buckling occurring because of this. 


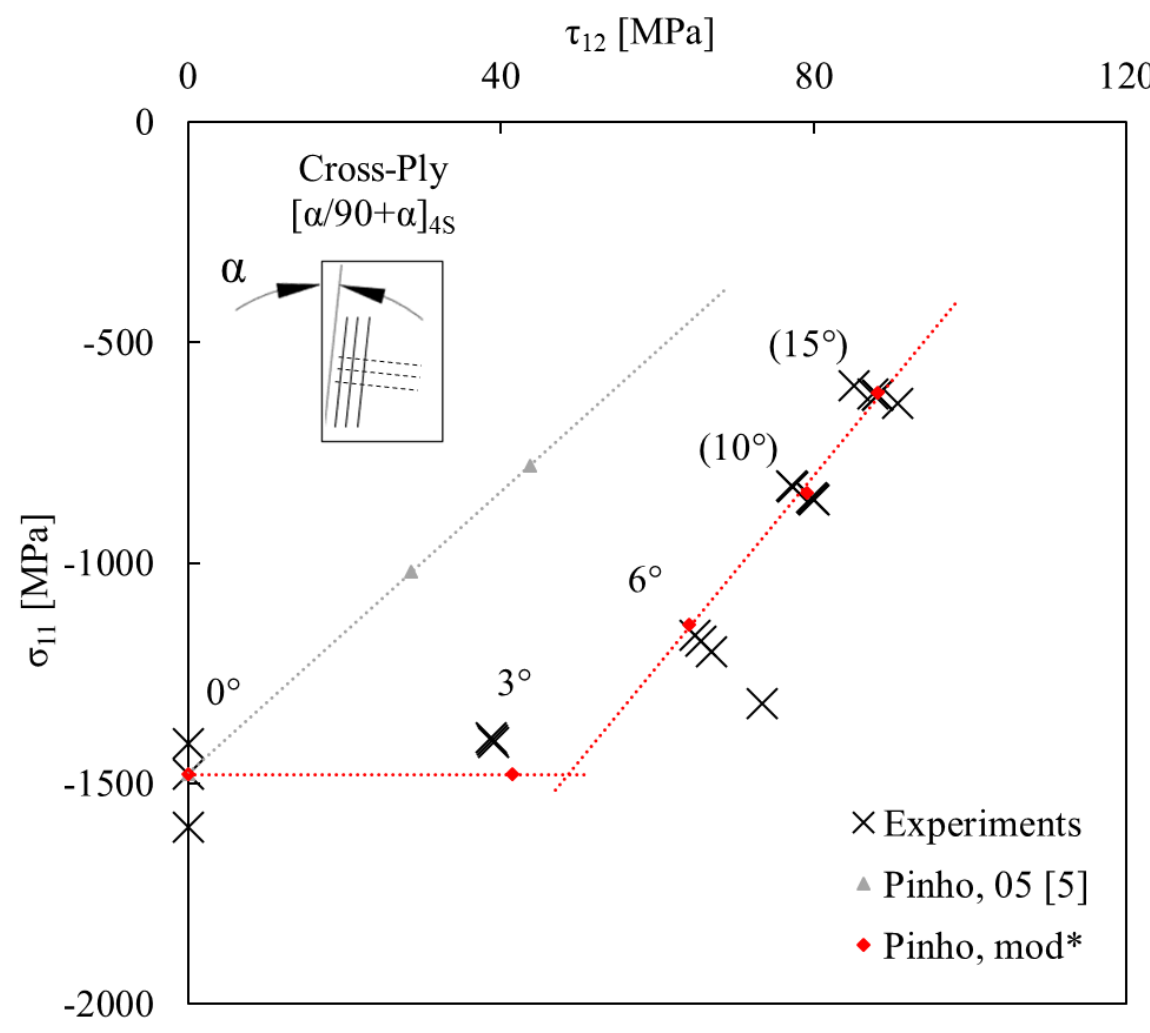

452 Figure 14. Longitudinal $\left(\sigma_{11}\right)$ vs shear $\left(\tau_{12}\right)$ stress at failure for the 0, 3, 6, 10 and $15^{\circ} \mathrm{CP} C u b$ 453 specimens, extracted using CLT. Brackets on 10 and $15^{\circ}$ results indicate that a corrwecting factor 454 has been applied to correct for fibre rotation. Grey markers indicate predicted failure stresses for 455 each case using the fibre kinking theory proposed by Pinho [5] and red markers indicate predictions 456 using the proposed modification. Numerical predictions were only calculated for the five off-axis 457 loading cases, dotted trend lines are extrapolated from these results.

458 This change in predicted cause of failure, from mechanical instability to IFF failure of the supporting 459 matrix, seems to agree well with the experimental results, which show little effect of the shear stress 460 between the $0^{\circ}$ and $3^{\circ}$ tests followed by a significant drop as the off-axis angle increases. In addition, 461 it would also help to explain the differences observed in the experiments (Figure 10), as the failure 462 mode appears to become more stable and matrix dominated with greater off-axis angles.

463 Overall, however, these results show that there is still work to be done on the prediction of fibre 464 kinking failure under combined, or off-axis, loads. Complex physically-based criteria like Pinho's, 
465 appear unable to capture the effects of shear, indicating that some of the driving failure mechanisms 466 may not yet be fully understood. The proposed modification to Pinho's criteria suggests one potential 467 explanation but may still be a pragmatic simplification of the micro-scale fibre rotation and matrix 468 damage mechanisms. Therefore, while the initial results appear to show good agreement, further 469 research is needed on the micro-mechanical behaviour of fibre composites under combined 470 compression and shear.

\section{Conclusions}

472 A series of longitudinal compression tests have been carried out on unidirectional and cross-ply

473 IM7/8552 composite laminates, with the aim of finding an optimal test method for the determination 474 of fibre compression strength.

475 For the UD samples, it resulted extremely challenging to produce reliable measurements, as the 476 material proved highly sensitive to specimen geometry and boundary conditions. The CP specimens, 477 on the other hand, produced much more reliable results, which were not noticeably affected by either 478 specimen geometry or boundary conditions.

479 Therefore, considering the fact that the CP samples are also better than UD ones in representing 480 practical multi-directional structures, the cubic CP sample is recommended throughout this work for 481 characterizing fibre kinking strength.

482 In addition, the same CP specimen design was used with fibre orientations of $0,3,6,10$ and 15 483 degrees to the loading axis to study the effect of shear on the fibre compression strength. This proved 484 to be a reliable and much simpler approach to obtaining this type of data compared to previous 485 experiments in the literature and provided additional data points for the evaluation of fibre 486 compression failure criteria. 
487 Finally, this data was used to evaluate the fibre kinking theory proposed by Pinho in [5] and a minor 488 modification is proposed, which improves predictions in cases with combined longitudinal 489 compression $\left(\sigma_{11}\right)$ and in-plane shear $\left(\tau_{12}\right)$.

\section{Acknowledgements}

491 The authors would like to acknowledge Rolls-Royce plc, for their continuing support through the 492 Solid Mechanics University Technology Centre at the University of Oxford.

\section{References}

494 [1] Rosen BW. Mechanics of composite strengthening. Fiber Compos. Mater. Semin. Am. Soc.

[2] Budiansky B, Fleck NA. Compressive failure of fibre composites. J Mech Phys Solids 1993;41:183-211. doi:10.1016/0022-5096(93)90068-Q. Met., Ohio: American Society for Metals; 1965, p. 37-75.

[4] Pinho S, Darvizeh R, Robinson P, Schuecker C, Camanho P. Material and structural response of polymer-matrix fibre-reinforced composites n.d. doi:10.1177/0021998312454478.

[3] Pinho ST, Iannucci L, Robinson P. Physically-based failure models and criteria for laminated fibre-reinforced composites . Part I: Development. Compos Part A Appl Sci Manuf 2006;37:63-73. doi:10.1016/j.compositesa.2005.04.016.

[7] Ploeckl M, Kuhn P, Grosser J, Wolfahrt M, Koerber H. A dynamic test methodology for 509 analyzing the strain-rate effect on the longitudinal compressive behavior of fiber-reinforced 
composites. Compos Struct 2017;180:429-38. doi:10.1016/j.compstruct.2017.08.048.

511 [8] ASTM D6641 / D6641M - 09 Standard Test Method for Compressive Properties of Polymer Matrix Composite Materials Using a Combined Loading Compression (CLC) Test Fixture 2009. doi:10.1520/D6641_D6641M-09.

514 [9] Kaddour A, Hinton M, Smith P, Li S. Mechanical properties and details of composite laminates for the test cases used in the third world-wide failure exercise. J Compos Mater

[10] Johnson W, Masters J, Wilson D, Welsh J, Adams D. Unidirectional Composite Compression Strengths Obtained by Testing Cross-Ply Laminates. J Compos Technol Res 1996;18:241. doi:10.1520/CTR10109J.

[12] Hexcel. HexPly 8552 Data Sheet. n.d.

[13] Lafarie-Frenot MC, Touchard F. Comparative in-plane shear behaviour of long-carbon-fibre composites with thermoset or thermoplastic matrix. Compos Sci Technol 1994;52:417-25. doi:10.1016/0266-3538(94)90176-7.

[14] Shuart MJ. Failure of compression-loaded multidirectional composite laminates. AIAA J 1989;27:1274-9. doi:10.2514/3.10255.

[15] Soden PD, Hinton MJ, Kaddour AS. Biaxial test results for strength and deformation of a range of E-glass and carbon fibre reinforced composite laminates: failure exercise benchmark data. Compos Sci Technol 2002;62:1489-514. doi:10.1016/S0266-3538(02)00093-3.

532 [16] Hine PJ, Duckett RA, Kaddour AS, Hinton MJ, Wells GM. The effect of hydrostatic pressure 
on the mechanical properties of glass fibre/epoxy unidirectional composites. Compos Part A Appl Sci Manuf 2005;36:279-89. doi:10.1016/j.compositesa.2004.06.004.

[17] Shin ES, Pae KD. Effects of Hydrostatic Pressure on In-Plane Shear Properties of Graphite/Epoxy Composites n.d.

[18] Hoppel CPR, Bogetti TA, Gillespie JW. Literature Review-Effects of Hydrostatic Pressure on the Mechanical Behavior of Composite Materials. J Thermoplast Compos Mater 1995. doi:10.1177/089270579500800403.

[19] Welsh JS, Adams DF. An Experimental Investigation of the Mini-Sandwich Laminate as Used

[20] Czabaj MW, Riccio ML, Whitacre WW. Numerical reconstruction of graphite/epoxy to Obtain Unidirectional Composite Compression Strengths. J Compos Mater 1997;31:293314. doi:10.1177/002199839703100304.

composite microstructure based on sub-micron resolution X-ray computed tomography. Compos Sci Technol 2014;105:174-82. doi:10.1016/J.COMPSCITECH.2014.10.017.

[21] Erice B, Thomson D, Ponnusami SA, Pathan M V., Petrinic N. On the Rate-dependent Plasticity Modelling of Unidirectional Fibre-reinforced Polymeric Matrix Composites. EPJ Web Conf 2018;183:01055. doi:10.1051/epjconf/201818301055.

[22] Koerber H, Xavier J, Camanho PP. High strain rate characterisation of unidirectional carbonepoxy IM7-8552 in transverse compression and in-plane shear using digital image correlation. Mech Mater 2010;42:1004-19. doi:10.1016/j.mechmat.2010.09.003.

[23] Naya F, Herráez M, Lopes CS, González C, Van der Veen S, Pons F. Computational micromechanics of fiber kinking in unidirectional FRP under different environmental $\begin{array}{llll}\text { conditions. } & \text { Compos } & \text { Sci } & \text { Technol }\end{array}$ doi:10.1016/J.COMPSCITECH.2017.03.014. 
PHYSICALLY BASED PHENOMENOLOGICAL MODELS. Compos Sci Technol 1998;58:1045-67. doi:10.1016/S0266-3538(96)00140-6.

559 [25] Pinho ST. Modelling failure of laminated composites using physically-based failure models. 5602005

561 [26] Bergan A, Herráez M, González C, Lopes C. Development of a Mesoscale Finite Element 562 Constitutive Model for Fiber Kinking. 2018 AIAA/ASCE/AHS/ASC Struct. Struct. Dyn. 563 Mater. Conf., Reston, Virginia: American Institute of Aeronautics and Astronautics; 2018. 564 doi:10.2514/6.2018-1221. 
2019-03-25

\section{A study on the longitudinal compression strength of fibre reinforced composites under uniaxial and off-axis loads using cross-ply laminate specimens.}

\section{Thomson, Daniel}

Elsevier

Thomson D, Cui H, Erice B, Petrinic N. (2019) A study on the longitudinal compression strength of fibre reinforced composites under uniaxial and off-axis loads using cross-ply laminate specimens. Composites Part A: Applied Science and Manufacturing, Volume 121, June 2019, pp. 213-222

https://doi.org/10.1016/j.compositesa.2019.03.034

Downloaded from Cranfield Library Services E-Repository 